Tetrahedron Letters

journal homepage: www.elsevier.com

\title{
A General Method for Synthesis of cis-Dicarbonyl Epoxides through DBU/LiBr- Cocatalyzed Cyclization of $\alpha, \beta$-Dicarbonyl Peroxides
}

\author{
Zhenzhen Zong, Xiaohui Bai, Shenglin Lu, and Zhiping Li* \\ Department of Chemistry, Renmin University of China, Beijing 100872, China
}

\section{ARTICLE INFO}

Article history:

Received

Received in revised form

Accepted

Available online

\section{Keywords:}

Peroxide

Epoxide

Cyclization

Disatereoselectivity

Cocatalysis

\section{ABSTRACT}

A general method for synthesis of cis-dicarbonyl epoxides is developed. The highly diastereoselective cyclization of $\alpha, \beta$-dicarbonyl peroxides is achieved by DBU/LiBr cocatalysis. The coordination of lithium ion with two carbonyl groups is proposed for the control of cis selectivity.

2013 Elsevier Ltd. All rights reserved.
Epoxides are highly useful intermediates and building blocks for synthesis of biologically active compounds and natural products. ${ }^{1}$ Epoxidation of alkenes by activated oxygen source presents the most important method for synthesis of epoxides. ${ }^{2}$ Great progresses have been achieved for epoxidation of electronrich alkenes. ${ }^{2,3}$ However, the successful strategies for synthesis of electron-deficient epoxides such as carbonyl epoxides are still limited. ${ }^{4}$ Weitz-Scheffer epoxidation of $\alpha, \beta$-unsaturated ketones using hydroperoxides in the presence of base is one of useful methods for the preparation of $\alpha, \beta$-epoxy ketones via the key peroxide enolate intermediate $\mathbf{A}$ (Scheme 1, a). ${ }^{5}$ transDisubstituted epoxides were selectively formed due to the steric effect. ${ }^{\text {aa }}$ Darzens reaction of aldehydes (or ketones) and $\alpha$-halo esters under basic conditions presents a general method for the formation of $\alpha, \beta$-epoxy esters (Scheme 1, b). ${ }^{1 \mathrm{a}, 6}$ Although multisubstituted epoxides could be achieved, a mixed diastereomers were obtained generally in Darzen reaction. ${ }^{6 a}$ Recently, we developed an iron-catalyzed three-component strategy for synthesis of a variety of $\beta$-carbonyl peroxides, ${ }^{7}$ which were envisioned as the precursors of the peroxide enolate intermediate A in Weitz-Scheffer epoxidation by base-catalyzed deprotonation. Accordingly, we developed an efficient pyrrolidine-catalyzed cyclization of $\alpha, \beta$-dicarbonyl peroxides for selective synthesis of cis-dicarbonyl epoxides (Scheme 1, c). ${ }^{8,9}$ The developed method was successfully applied for the selective construction of the desired epoxide unit in total synthesis of $( \pm$ )-Clavilactones A, B, and proposed D. ${ }^{10}$ However, pyrrolidine was ineffective for the cyclization of $\beta$-ester peroxides $\left(R^{1}=\mathrm{OR}\right.$ in Scheme $\left.1, \mathrm{c}\right)$ due to the weak basicity of pyrrolidine and the diastereoselectivity of the cyclization of $\beta$-carbonyl peroxides $\left(\mathrm{R}^{1}=\right.$ alkyl in Scheme 1 , e) was not satisfied. ${ }^{8}$ To overcome the limitations, we here report a general method for synthesis of cis-dicarbonyl epoxides through $\mathrm{DBU} / \mathrm{LiBr}$-cocatalyzed cyclization of $\alpha, \beta$-dicarbonyl peroxides under the mild reaction conditions (Scheme 1, d).

(a) Weitz-Scheffer epoxidation

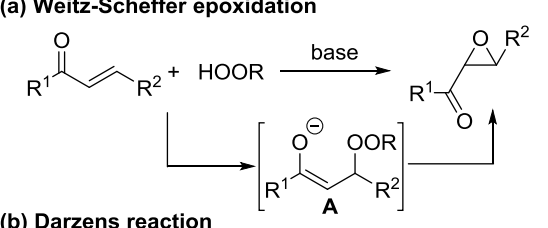

(b) Darzens reaction

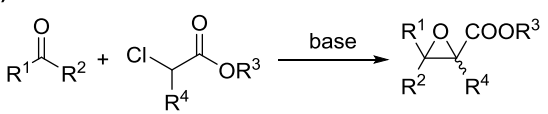

(c) Cyclization of $\beta$-carbonyl peroxides

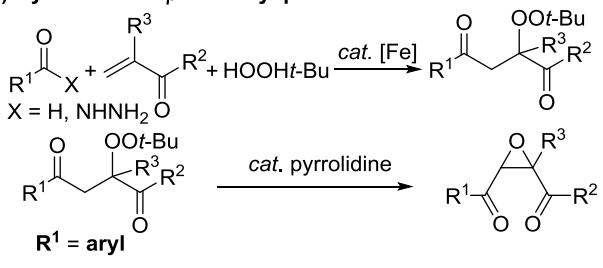

(d) A general method by $\mathrm{DBU} / \mathrm{LiBr}$ cocatalysis (This Work)

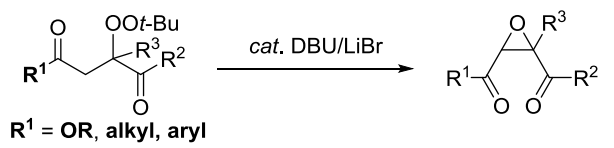

Scheme 1. Synthesis of electron-deficient epoxides.

To initiate our studies, we chose dimethyl 2-(tertbutylperoxy)-2-methylsuccinate $\mathbf{1 a}$ as the model substrate to

* Corresponding author. Tel.: +86-10-6251-4226; fax: +86-10-6251-6444; e-mail: zhipingli@ ruc.edu.cn 
establish the reaction conditions (Table 1). Pyrrolidine was failed to promote the intramolecular cyclization of $\mathbf{1 a}$ due to the weak basicity of pyrrolidine (entry 1 ). When DBN and DBU were applied, the epoxides, $\mathbf{2 a}$ and $\mathbf{2} \mathbf{a}^{\prime}$, were obtained in low yields and poor diastereoselectivities (entries 2 and 3). A 94\% yield of cis-dicarbonyl epoxide $\mathbf{2 a}$ was achieved by the addition of $\mathrm{LiBr}$ into the reaction (entry 4). Notably, the cyclization occurred by the combination of pyrrolidine and $\mathrm{LiBr}$, albeit in low efficiency (entry 5). These results indicated that (1) $\mathrm{LiBr}$ plays a role of Lewis acid to activate the acidity of $\alpha-\mathrm{H}$ at the ester group (the efficiency); (2) the cis selectivity of the cyclization is most likely attributed to the coordination of lithium ion with two carbonyl groups of $\mathbf{1 a}$ (the selectivity). Furthermore other additives were investigated (entries 6-12). Mg, Zn, K, Na, and $\mathrm{Ca}$ ions were all ineffective for the present cyclization (entries 6-10), while $\mathrm{LiCl}$ and $\mathrm{LiI}$ gave the similar results as $\mathrm{LiBr}$ (entries 11 and 12). The results demonstrated that lithium ion plays a unique and important role for the cyclization. It should be noted that the efficiency of the reaction is reduced by a reducing amount of DBU (entry 13).

Table 1. Optimization of the reaction conditions ${ }^{\mathrm{a}}$

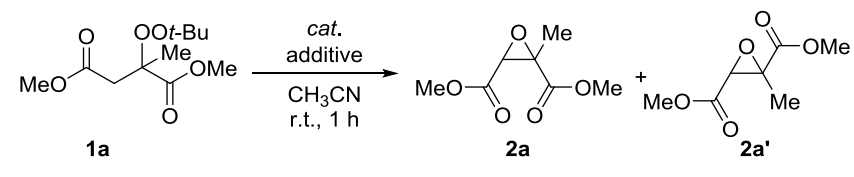

\begin{tabular}{|c|c|c|c|c|c|}
\hline entry & cat. & additive & $\mathbf{2 a}(\%)^{\mathbf{b}}$ & $\mathbf{2 a}^{\prime}(\%)^{\mathbf{b}}$ & d.r. \\
\hline 1 & pyrrolidine & - & - & - & - \\
\hline 2 & DBN & - & 5 & 4 & $55: 45$ \\
\hline 3 & DBU & - & 14 & 11 & $55: 45$ \\
\hline 4 & DBU & $\mathrm{LiBr}$ & 94 & 3 & $97: 3$ \\
\hline 5 & pyrrolidine & $\mathrm{LiBr}$ & 21 & 3 & $87: 13$ \\
\hline 6 & DBU & $\mathrm{MgCl}_{2}$ & $<5$ & $<5$ & - \\
\hline 7 & DBU & $\mathrm{ZnCl}_{2}$ & $<5$ & $<5$ & - \\
\hline 8 & DBU & $\mathrm{KBr}^{2}$ & 11 & 10 & $52: 48$ \\
\hline 9 & DBU & $\mathrm{NaCl}$ & 12 & 10 & $55: 45$ \\
\hline 10 & DBU & $\mathrm{CaCl}_{2}$ & 6 & 5 & $55: 45$ \\
\hline 11 & DBU & $\mathrm{LiCl}^{2}$ & 83 & 3 & $97: 3$ \\
\hline 12 & DBU & $\mathrm{LiI}$ & 85 & 3 & $97: 3$ \\
\hline 13 & DBU & $\mathrm{LiBr}^{\mathrm{c}}$ & 64 & 2 & $97: 3$ \\
\hline
\end{tabular}

a Conditions: 1a $(0.5 \mathrm{mmol})$, cat. $(0.15 \mathrm{mmol}, 30 \mathrm{~mol} \%)$, additive $(0.15$ mmol, $30 \mathrm{~mol} \mathrm{\%}), \mathrm{CH}_{3} \mathrm{CN}(2 \mathrm{~mL})$, r.t., 1 h, under $\mathrm{N}_{2}$.

${ }^{\mathrm{b}} \mathrm{NMR}$ yield.

${ }^{\mathrm{c}} \mathrm{DBU}(0.05 \mathrm{mmol}, 10 \mathrm{~mol} \%)$

Subsequently, the scope of the substrates was investigated under the optimal reaction conditions (Tables 2 and 3). A variety of $\alpha, \beta$-diester peroxides $\mathbf{1}$ were transformed smoothly into the desired cis-dicarbonyl epoxides 2 with excellent diastereoselectivities (Table 2). Ester groups showed no influence on the selectivity and reactivity of the cyclization (entries 1-3). The substrates bearing alkyl and aryl groups $\left(\mathrm{R}^{3}\right)$ were also applicable for the present cyclization (entries 4-13). Although the efficiency of the cyclization was not affected by the electronic effect of aryl groups (entries 9-12), an electron-withdrawing group such as $\mathrm{Cl}$ group on the phenyl ring dramatically reduced the diastereoselectivity to 9:1 (entry 12). We hypothesized that the coordinative ability of $\alpha$-ester group with lithium ion was reduced by electron-withdrawing group $\mathrm{R}^{3}$ and thus the cyclization lose the diastereoselectivity.

Table 2. Scope of $\beta$-ester peroxides $\mathbf{1}^{\mathrm{a}}$

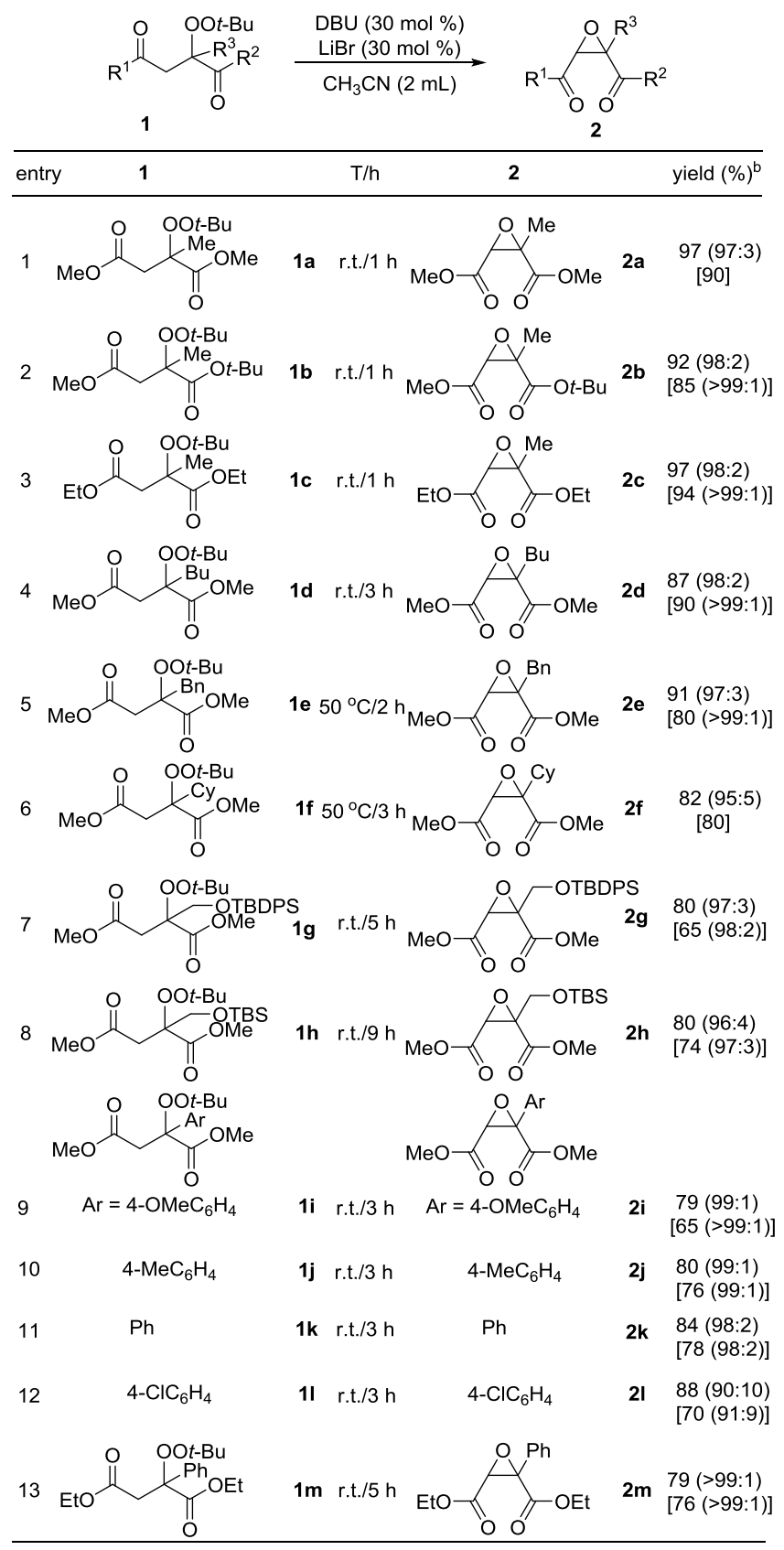

${ }^{a}$ Conditions: 1 (0.5 mmol), DBU (0.15 mmol, $\left.30 \mathrm{~mol} \%\right), \mathrm{LiBr}(0.15 \mathrm{mmol}$, $30 \mathrm{~mol} \%), \mathrm{CH}_{3} \mathrm{CN}(2 \mathrm{~mL})$, under $\mathrm{N}_{2}$.

${ }^{\mathrm{b}}$ The yields and ratios of 2 were determined by ${ }^{1} \mathrm{H}$ NMR; the isolated yields and the ratios of two diastereomers were given in square brackets.

To demonstrate the generality of the present protocol in cisdicarbonyl epoxide synthesis, the cyclization of various $\beta$ carbonyl peroxides were further investigated by using pyrrolidine (method A), DBU (method B), and DBU/LiBr (method C) (Table 3). By comparing the results of the applied methods, we found that the method of $\mathrm{DBU} / \mathrm{LiBr}$ cocatalysis (method $\mathbf{C}$ ) could not only instead pyrrolidine catalysis $\left(\mathrm{R}^{1}=\text { aryl; entries } 1 \text { and } 2\right)^{8}$ but also successfully apply for alkyl $\left(\mathrm{R}^{1}\right)$ substrates (entries 3 and 4 ). As an extreme example, trans-dicarbonyl epoxide $\mathbf{2} \mathbf{r}^{\prime}$ was selectively obtained by methods $\mathbf{A}$ and $\mathbf{B}$ due to the steric effect, while the ratio of cis-/trans-isomers was improved to $44: 56$ by 
$\mathrm{DBU} / \mathrm{LiBr}$ cocatalysis (entry 5). The results strongly supported that lithium ion plays a key role in the diastereoselective cyclization of $\alpha, \beta$-dicarbonyl peroxides.

Table 3. Scope of $\beta$-keto peroxides $\mathbf{1}^{\mathrm{a}}$

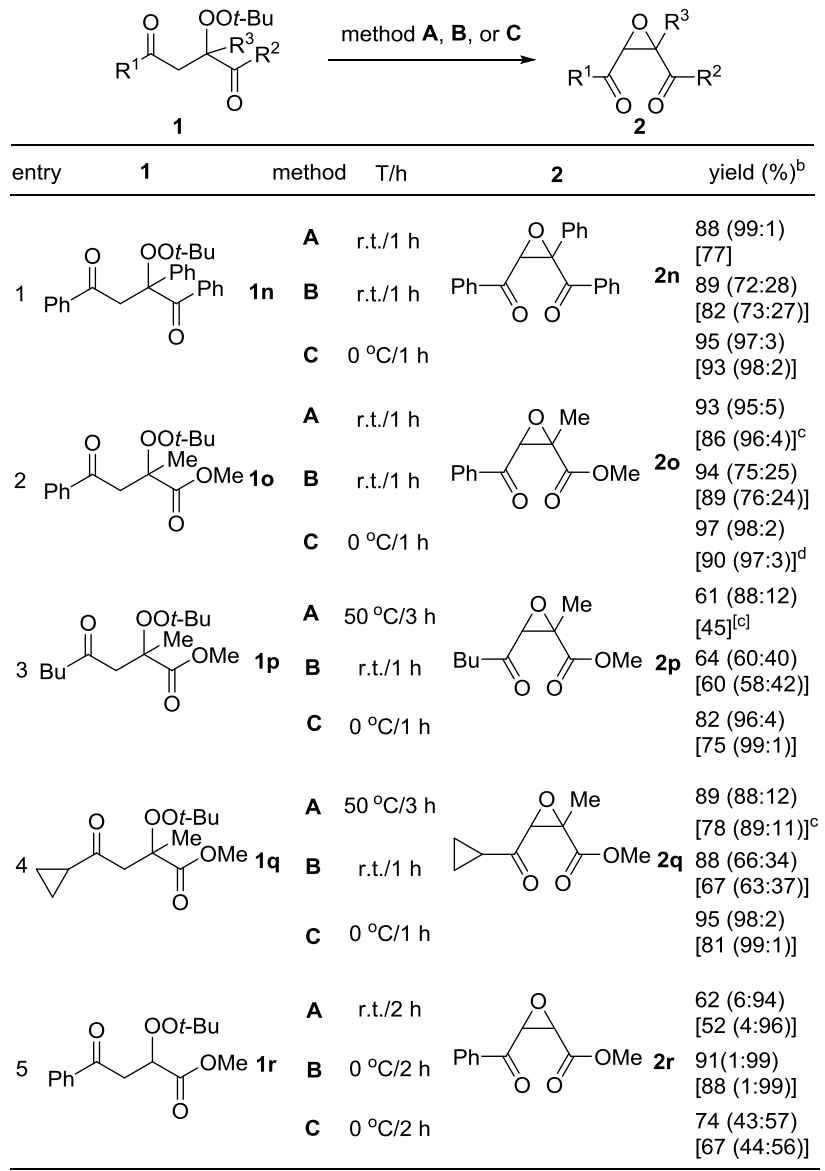

${ }^{a}$ Conditions: method A: $1(0.5 \mathrm{mmol})$, pyrrolidine $(0.25 \mathrm{mmol}, 50 \mathrm{~mol} \%)$, $\mathrm{CH}_{3} \mathrm{CN}(2 \mathrm{~mL})$, under $\mathrm{N}_{2}$; method B: 1 (0.5 mmol), DBU $(0.15 \mathrm{mmol}, 30$ mol \% ), $\mathrm{CH}_{3} \mathrm{CN}(2 \mathrm{~mL})$, under $\mathrm{N}_{2}$; method C: 1 (0.5 mmol), DBU (0.15 mmol, $30 \mathrm{~mol} \%$ ), $\mathrm{LiBr}(0.15 \mathrm{mmol}, 30 \mathrm{~mol} \%), \mathrm{CH}_{3} \mathrm{CN}(2 \mathrm{~mL})$, under $\mathrm{N}_{2}$.

${ }^{b}$ Reported yields were based on $\mathbf{1}$ and determined by ${ }^{1} \mathrm{H}$ NMR using an internal standard; isolated yields were given in parentheses.

${ }^{\mathrm{c}}$ Reference 8

${ }^{\mathrm{d}} \mathrm{DBU}(0.05 \mathrm{mmol}, 10 \mathrm{~mol} \%)$

To further examine the possible roles of lithium ion in the cyclization, control experiments were conducted (eqs 1 and 2). When $\beta$-ester peroxide 3, without an $\alpha$-ester group, was applied, the selectivity of the formation $\mathbf{4}$ and $\mathbf{4}^{\prime}$ was dramatically dropped either with $\mathrm{LiBr}$ or without $\mathrm{LiBr}$ (eq 1). Furthermore, 2a and $2 \mathbf{a}^{\prime}$ ' were obtained in $14 \%$ and $12 \%$ yields respectively when 2.2.2-cryptand, one of cationic trapping agents, ${ }^{11}$ was added into the model reaction (eq 2). The result was the same as the entry 3 in Table 1, which clearly indicated that the high diastereoselectivity of the cyclization of $\alpha, \beta$-dicarbonyl peroxides $\mathbf{1}$ to cis-dicarbonyl epoxides 2 by $\mathrm{DBU} / \mathrm{LiBr}$ cocatalysis is most likely due to the coordination of lithium ion with two carbonyl groups of $\mathbf{1}$.

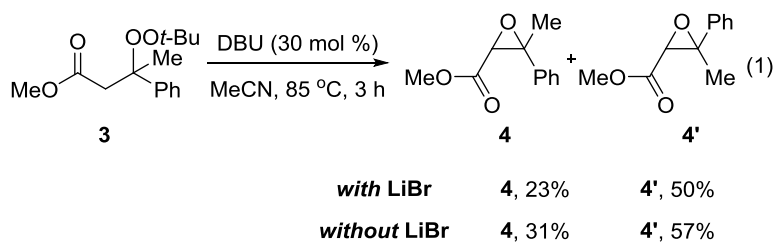

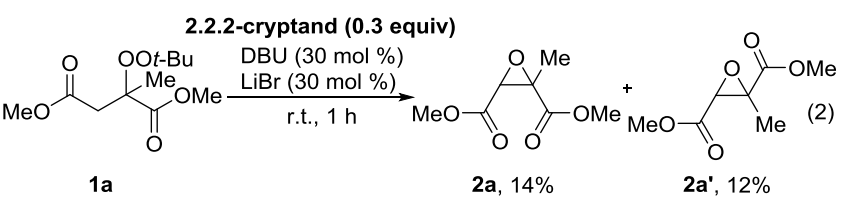

In addition, the kinetic isotope effect (KIE) experiments were conducted to probe the nature of the deprotonation step in the cyclization process (Scheme 2). Kinetic isotope effects $\left(\mathrm{k}_{\mathrm{H} / \mathrm{D}}=2\right)$ were observed from intermolecular competition (Scheme 2, a). In addition, two parallel reactions give rise to a $\mathrm{k}_{\mathrm{H}} / \mathrm{k}_{\mathrm{D}}$ value of 3 (Scheme 2, b). These results suggested that $\mathrm{C}-\mathrm{H}$ cleavage of $\alpha-$ site of ester group is likely involved in the rate-determining step.

(a) KIE from an intermolecular competition

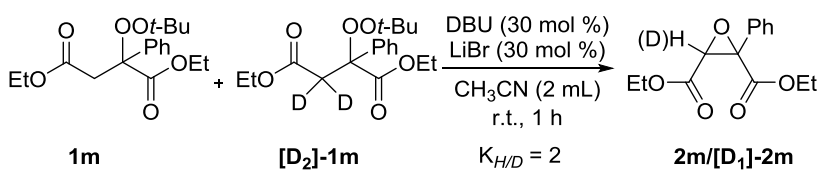

(b) KIE from two parallel reactions

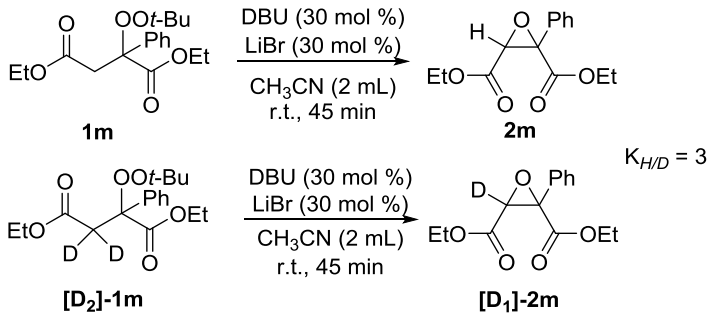

Scheme 2. KIE experiments.

Based on our results and the literature's reports, ${ }^{12}$ a tentative reaction pathway was proposed for $\mathrm{DBU} / \mathrm{LiBr}$ cocatalyzed diastereoseletive cyclization of $\alpha, \beta$-dicarbonyl peroxides $\mathbf{1}$ to $\mathrm{cis}$ dicarbonyl epoxides $\mathbf{2}$ (Scheme 3). Initially, lithium ion coordinates with dicarbonyl groups of $\mathbf{1}$ to generate a key cyclic intermediate $\mathbf{B}$, by which both the efficiency and diastereoseletivity of the cyclization were greatly enhanced as shown as entries 1-5 of Table 1. Deprotonation of $\mathbf{B}$ gives $\mathbf{C}$, which subsequently undergoes intramolecular cyclization to form the final expoxide product 2 . DBU and $\mathrm{LiBr}$ are regenerated by the releasing of tert-butanol $(\mathrm{HO} t-\mathrm{Bu})$ as the sole byproduct of the cyclization.

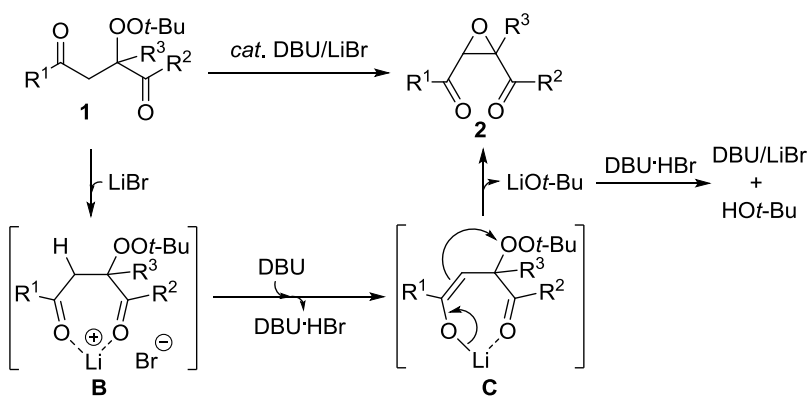

Scheme 3. A proposed mechanism.

In conclusion, we have demonstrated a general method for synthesis of cis-dicarbonyl epoxides by DBU/LiBr cocatalysis. A variety of multisubstutited epoxides were synthesized efficiently and selectively, which presents a practical alternative method for synthesis of electron-deficient epoxides. The lithium salt plays key roles for the efficiency and diastereoseletivity of the cyclization, in which the coordination of lithium ion with two 
carbonyl groups is proposed. Further studies on the mechanism and the applications are in progress.

Acknowledgment. Financial support from the National Science Foundation of China (21272267), State Key Laboratory of Heavy Oil Processing (SKLOP201401001), and Beijing National Laboratory for Molecular Sciences (BNLMS).

Supporting information available: Experimental procedures, spectrum data, and NMR spectra of the compounds. This material is available free of charge via the Internet at

\section{References and notes}

1. (a) He, J.; Ling, J.; Chiu, P. Chem. Rev. 2014, 114, 8037-8128; (b) Huang, C.-Y.; Doyle, A. G. Chem. Rev. 2014, 114, 8153-8198; (c) Snape, T. J. Chem. Soc. Rev. 2007, 36, 1823-1842; (d) Drahl, C.; Cravatt, B. F.; Sorensen, E. J. Angew. Chem. Int. Ed. 2005, 44, 5788-5809; (e) Marco-Contelles, J.; Molina, M.; Anjum, S. Chem. Rev. 2004, 104, 2857-2899; (f) Jacobsen, E. N. Acc. Chem. Res. 2000, 33, 421-431.

2. (a) Zhu, Y.; Wang, Q.; Cornwall, R. G.; Shi, Y. Chem. Rev. 2014, 114, 8199-8256; (b) De Faveri, G.; Ilyashenko, G.; Watkinson, M. Chem. Soc. Rev. 2011, 40, 1722-1760; (c) Xia, Q.-H.; Ge, H.-Q.; Ye, C.-P.; Liu, Z.-M.; Su, K.-X. Chem. Rev. 2005, 105, 1603-1662; (d) McGarrigle, E. M.; Gilheany, D. G. Chem. Rev. 2005, 105, 1563-1602; (e) Yang, D. Acc. Chem. Res. 2004, 37, 497-505; (f) Lane, B. S.; Burgess, K. Chem. Rev. 2003, 103, 2457-2473.

3. (a) Wong, O. A.; Shi, Y. Chem. Rev. 2008, 108, 3958-3987; (b) Shi, Y. Acc. Chem. Res. 2004, 37, 488-496; (c) Frohn, M.; Shi, Y. Synthesis 2000, 14, 1979-2000; (d) Katsuki, T.; Martin, V. S. Org. React. 1996, 48, 1-300; (e) Johnson, R. A.; Sharpless, K. B. In Catalytic Asymmetric Synthesis, Ojima, I., Ed.; VCH: New York, 1993, pp. 103-158; (f) Johnson, R. A.; Sharpless, K. B. In Comprehensive Organic Synthesis, Trost, B. M.; Fleming, I., Eds., Pergamon Press: New York, 1991, Vol. 7, pp. 389-436.

4. (a) Xu, M.-H.; Tu, Y.-Q.; Tian, J.-M.; Zhang, F.-M.; Wang, S.-H.; Zhang, S.-H.; Zhang, X.-M. Tetrahedron: Asymmetry 2016, 27, 294-300; (b) Zeng, C.; Yuan, D.; Zhao, B.; Yao, Y. Org. Lett. 2015, 17, 2242-2245; (c) Qian, Q.; Tan, Y.; Zhao, B.; Feng, T.; Shen, Q.; Yao, Y. Org. Lett. 2014, 16, 4516-4519; (d) Davis, R. L.; Stiller, J.; Naicker, T.; Jiang, H.; Jørgensen, K. A. Angew. Chem. Int. Ed. 2014, 53, 7406-7426; (e) Wang, B.; Wang, S.; Xia, C.; Sun, W. Chem. Eur. J. 2012, 18, 7332-7335; (f) Chu, Y.; Liu, X.; Li, W.; Hu, X.; Lin, L.; Feng, X. Chem. Sci. 2012, 3, 19962000; (g) Weiß, K. M.; Tsogoeva, S. B. Chem. Rec. 2011, 11, 1839; (h) Russo, A.; Lattanzi, A. Org. Biomol. Chem. 2010, 8, 26332638; (i) Wu, M.; Wang, B.; Wang, S.; Xia, C.; Sun, W. Org. Lett. 2009, 11, 3622-3625; (j) Li, Y.; Liu, X.; Yang, Y.; Zhao, G. J. Org. Chem. 2007, 72, 288-291; (k) Sello, G.; Fumagalli, T.; Orsini, F. Current Organic Synthesis 2006, 3, 457-476; (1) Porter, M. J.; Skidmore, J. Chem. Commun. 2000, 1215-1225.

5. Weitz, E.; Scheffer, A. Ber. Dtsch. Chem. Ges. 1921, 54, 2327.

6. (a) Yliniemelä, A.; Brunow, G.; Flügge, J.; Teleman, O. J. Org. Chem. 1996, 61, 6723-6726; (b) Ballester, M. Chem. Rev. 1955, $55,283-300$.

7. (a) Zong, Z.; Lu, S.; Wang, W.; Li, Z. Tetrahedron Lett. 2015, 56, 6719-6721; (b) Liu, K.; Li, Y.; Zheng, X.; Liu, W.; Li, Z. Tetrahedron 2012, 68, 10333-10338; (c) Liu, W.; Li, Y.; Liu, K.; Li, Z. J. Am. Chem. Soc. 2011, 133, 10756-10759.

8. Liu, K.; Li, Y.; Liu, W.; Zheng, X.; Zong, Z.; Li, Z. Chem. Asian J. 2013, 8, 359-363.

9. One-pot procedures for the synthesis of $\alpha, \beta$-epoxy ketones from alkenes and aldehydes: (a) 7c; (b) Chen, S.; Shao, Z.; Fang, Z.; Chen, Q.; Tang, T.; Fu, W.; Zhang, L.; Tang, T. J. Catal. 2016 338, 38-46; (c) Wei, W.-T.; Yang, X.-H.; Li, H.-B.; Li, J.-H. Adv. Synth. Catal. 2015, 357, 59-63; (d) Li, J.; Wang, D. Z. Org. Lett. 2015, 17, 5260-5263; (e) Ke, Q.; Zhang, B.; Hu, B.; Jin, Y.; Lu, G. Chem. Commun. 2015, 51, 1012-1015; (f) Reddi, R. N.; Prasad, P. K.; Sudalai, A. Angew. Chem. Int. Ed. 2015, 54, 14150-14153; (g) Xiang, M.; Ni, X.; Yi, X.; Zheng, A.; Wang, W.; He, M.; Xiong, J.; Liu, T.; Ma, Y.; Zhu, P.; Zheng, X.; Tang, T. ChemCatChem 2015, 7, 521-525.

10. Lv, L.; Shen, B.; Li, Z. Angew. Chem. Int. Ed. 2014, 53, 41644167.

11. Lehn, J.-M. Acc. Chem. Res. 1978, 11, 49-57.
12. (a) Bera, S.; Daniliuc, C. G.; Studer, A. Org. Lett. 2015, 17, 49404943; (b) Ugarriza, I.; Uria, U.; Carrillo, L.; Vicario, J. L.; Reyes, E. Chem. Eur. J. 2014, 20, 11650-11654; (c) Bera, S.; Samanta, R. C.; Daniliuc, C. G.; Studer, A. Angew. Chem. Int. Ed. 2014, 53, 9622-9626; (d) Ando, K.; Oishi, T.; Hirama, M.; Ohno, H.; Ibuka, T. J. Org. Chem. 2000, 65, 4745-4749; (e) Meth-Cohn, O.; Moore, C.; Taljaard, H. C. J. Chem. Soc. Perkin Trans. 1, 1988, 26632674. 


\section{Graphical Abstract}

To create your abstract, type over the instructions in the template box below.

Fonts or abstract dimensions should not be changed or altered.

A General Method for Synthesis of cis-

Leave this area blank for abstract info.

Dicarbonyl Epoxides through DBU/LiBr-

Cocatalyzed Cyclization of $\alpha, \beta$-Dicarbonyl

Peroxides

Zhenzhen Zong, Xiaohui Bai, Shenglin Lu, and Zhiping Li*

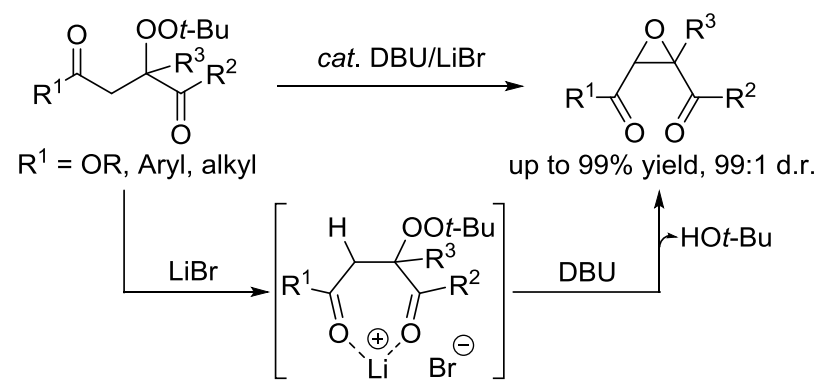

